\title{
Kindergarten Training Department
}

\section{Bertha M. Payne}

The courses offered in the kindergarten department of the Summer School are designed to help both the kindergartner and the primary teacher, in the belief that both need in most fundamentals the same study. When both classes of workers have a better grasp of the dominating instincts, impulses, and interests of childhood during the kindergarten age and the first school years the present break between the first grade and the kindergarten will disappear. The kindergartner needs an actual working knowledge of children beyond the play period; without it she cannot rightly measure the bearing of her training upon the child's later development. Similarly, the primary teacher needs an understanding of children in the play period of development, in order correctly to understand the youngest in her group. When she knows the conditions under which her class fresh from the kindergarten has lived, she can carry the children on without waste of effort.

The youngest children in the kindergarten are satisfied with simple forms of activity not aimed toward permanent results. When a little older they begin to plan, but are easily turned aside by accidents and suggestions; when still more developed, they plan more carefully and carry out the plans more persistently. When a child can plan a piece of work and keep on developing it from day to day he is usually ready for the more conscious work of the first grade. The play impulses, however, do not then stop short,

\section{Anne Elizabeth Allen}

but recur continually in different forms, which should be understood by the teacher and used in the best way. This is where a study of Froebel and of the kindergarten of early childhood proves itself helpful.

The representative plays of the kindergarten may develop into fuller dramatizations. The simple games may be followed by those demanding more skill. The building plays of the kindergarten may go on or be followed by construction work. Sloyd follows the easier occupations of the kindergarten. Singing, drawing, painting, and modeling increase steadily in definiteness and feeling for life.

For both kindergartner and teacher, then, we shall make a study of the psychology and pedagogy of play and work from earliest childhood into the first school years, also of the demands that life makes upon the child; and we shall consider the best means of keeping him in the right attitude toward others.

In these three endeavors we shall find great assistance from the interpretations that Froebel has given to child manifestations. What we find in Froebel may be supplemented, illustrated, or criticised by the later work in genetic psychology and child-study. We will use from these sources all that bears most directly upon the questions of play, toys, games, language, drawings, feeling for nature, and religious feeling.

Observation in the kindergarten and in the first grade will be found very helpful to those taking this course. 